\title{
The Near-Death Experience: An Ancient Truth, A Modern Mystery
}

\author{
Elizabeth W. Fenske, Ph.D. \\ International Association for Near-Death Studies
}

\begin{abstract}
The near-death experience (NDE), as an experience of wholeness, an adventure in consciousness, and a metaphoric encounter with light, links theoretical physics with the occult, the Primordial Tradition, and various religious belief systems. Light as image, vehicle, and first cause ties the NDE to mystical experience. Where science sees mystery, religion sees metaphoric truth; the NDE as spiritual quest and physical encounter beckons to both disciplines for explanation.
\end{abstract}

In any keynote address, one is caught between the desire to be all things to all people-truly to set the stage for all that follows-and the desire to raise issues that can be explored at greater depth not only while we are here together, but also in the future. If I have chosen either of these directions, it is probably the latter, because I believe the near-death experience (NDE) is part of a larger picture, one that is of enormous importance to each of us.

We come from many walks of life, with differing interests and needs; yet, all of us are concerned with the subject of the near-death experi-

Dr. Fenske is President of the International Association for Near-Death Studies, and is engaged in the private practice of psychotherapy and the integration of psychology and religion. This paper is a revised version of her keynote lecture presented at the International Association for Near-Death Studies First Annual Conference, Rosemont, PA, June 1989. Requests for reprints should be addressed to Dr. Fenske at 3310 Baring Street, Philadelphia, PA 19104. 
ence. This says something about the chord of truth that has been struck by the NDE, and it says something also about its mystery-its ability to intrigue the rational intellect and excite the deep center of the subjective, intuitive mind. Thus, our focus at this conference is the near-death experience as both ancient truth and modern mystery. In selecting this title, I sought to provide a structure within which the NDE might be considered both as it relates to science and as it touches the experiential and metaphysical realms.

In this address I will approach the NDE first as an experience of wholeness, second as an adventure in consciousness, and third as a metaphoric encounter with the essence of light. Each of these areas is associated with what might be called ancient truth, because each can chart its beginnings in humankind's spiritual search and subsequent religious expression. This is the domain of the subjective, the experiential aspect of nature and the heart.

Today, however, these same three areas of study (wholeness, consciousness, and light) are also the focus of empirical questions facing the scientific world. Where once we had a model for science based in objective reasoning and a model for religion based in faith, now the two are seen to overlap in crucial areas. While Albert Einstein, for instance, showed us mathematically the importance of perception to our concepts of time and space, mystics through the ages have reported dramatic experiences in which space and time were radically altered during moments of spiritual revelation. Since the near-death experiencer also encounters this radically altered reality, the NDE, and its related studies, may someday prove to be an aspect of the bridge between these two disciplines-science and religion. Thus, in a few years, we may discover that what we thought were separate, even competing models for science and religion have at their core the same reality, the same answer that each is seeking. If indeed these models come together at a future time, in a dimension of knowledge vastly expanded from our sense of it today, we will truly be forced to affirm, what some already believe, that spirit and matter are one.

\section{An Experience of Wholeness}

Although such an affirmation may find difficulties gaining acceptance in certain quarters today, it was once, in earlier times, an established first principle for a group of teachings known collectively as the occult. Taken literally, the word occult means hidden, and the hidden knowledge it describes pertains to certain fundamental rela- 
tionships that undergird the universe. Because the pursuit of occult understanding can be easily diverted to a quest for power, the practice of occultism has drawn to it persons and activities that have marred the original intent of the studies. That intent was transformation, not personal power.

In seeking to understand the workings of the human mind, we can easily find ourselves asking questions about the beginnings of the universe - the origins of matter, the essence of mind, the evolution of the two. To some extent the current conclusions of modern science find a commonality and consistency with certain teachings in the body of work known as Esoteric Philosophy (an aspect of occult studies). Although major discrepancies exist regarding the timescale and role of superphysical forces, nonetheless, many parallels are evident. Take, for instance, the work of the Russian occultist, Helen P. Blavatsky, in her book The Secret Doctrine (Hanson, 1988), and compare one short section with the words of Robert Jastrow, founder and director of NASA's Goddard Institute for Space Studies, in his book Until the Sun Dies (1977). Then look at both these excerpts in light of a quote from Genesis. Doss McDavid, in an article that first appeared in The Theosophical Research Journal, December 1984, drew the analogy between Jastrow and Blavatsky. I have added the Biblical reference. McDavid's comparison appears in H.P. Blavatsky and the Secret Doctrine (Hanson, 1988, p. 113), and I offer a portion of it below.

\section{A Scientist, an Occultist and A Biblical Account}

In his book, Jastrow (1977) is speaking of the birth of the universe and the evolution of living organisms:

Picture the radiant splendor of the moment of creation. Suddenly a world of pure energy flashes into being; light of unimaginable brightness fills the universe. (Hanson, 1988, p. 113)

Blavatsky's words also relate to a primordial moment:

Darkness radiates light ... Behold... the unparalleled refulgent glory: Bright Space, Son of Dark Space ... (Hanson, 1988, p. 113)

And, in Genesis 1:3-5 (Revised Standard Version) the great epic story of creation is offered in very similar language:

And God said, 'Let there be light'; and there was light. And God saw that the light was good; and God separated the light from the darkness. 
Like occultists, the physicists of this century have been particularly interested in fundamental relationships, and they have witnessed, in part, the disappearance of the so-called solid world of daily perception through the advent and acceptance of two important theories: relativity, and quantum mechanics. Between them, these two theoretical approaches have altered our traditional ideas of space, time, energy and matter, as well as our belief in determinism and the independence of the observed from the observer. When scientists begin to talk of particles and subatomic particles, and to speculate on the mysterious interactions between them, they often find themselves using the language of occultists.

\section{Three Scientists}

As we know, some physicists and scientists have been outspoken about the metaphysical implications of their current findings. Included with this group are three important figures whose work has been dedicated to uncovering the hidden order of the universe and to pointing the way toward wholeness, the experience of which is essential to each of us, both in physical terms and as spiritual reality. These three figures, Albert Einstein, David Bohm, and Rupert Sheldrake, are scientists whose work has bridged two quantum spheres. In briefly discussing their ideas, it is my intention to weave for us a web of thoughts related to an understanding of the near-death experience.

First among these scholars is the towering figure of Einstein. A backward child who did not speak until he was four and whose marks in school were only average, Einstein spent his life in vocal support of unpopular sentiments. A pacifist in Germany during World War I, he then opposed the Nazi rise to power, and in later years became both an ardent Zionist and an advocate of nuclear arms control.

In 1905, when he was twenty-six years old, Einstein published his Special Theory of Relativity. The same year he did his work on light quanta. Special Relativity was postulated based on his concern over Isaac Newton's idea of absolute motion (motion that takes place in space and time). The second element in his theory came from his interest in light. John Briggs and David Peat report that as a boy Einstein was fascinated by light and believed that "if he chased a beam of light with increasing speed, in the end he would run alongside it and see a stationary ripple in the ether" (Briggs and Peat, 1984, p. 57).

In this thought we can easily see the seeds of Einstein's work with relativity and quantum mechanics. It is not, however, this work that I 
want to discuss but rather his thoughts on the subjects of art, religion and science. In his book The World As I See It (1979), Einstein identified the highest form of religious experience as "cosmic religious feeling." Of this state he wrote:

The individual feels the nothingness of human desires and aims and the sublimity and marvelous order which reveal themselves both in nature and in the world of thought. He looks upon an individual existence as a sort of prison and wants to experience the universe as a single significant whole....

The religious geniuses of all ages have been distinguished by this kind of religious feeling which knows no dogma and no God conceived in man's image....

In my view, it is the most important function of art and science to awaken this feeling and keep it alive in those who are capable of it. (pp. 26-27).

Because scientists usually have a deep yearning to understand, they often see concepts in terms of the universe as a whole, and Einstein (1979) maintained that:

[the scientist's] religious feeling takes the form of a rapturous amazement at the harmony of natural law, which reveals an intelligence of such superiority that, compared with it, all the systematic thinking and acting of human beings is an utterly insignificant reflection. (pp. 28-29).

In contemplating that harmony of natural law, we might be led to the work of one of the most thrilling of contemporary physicists, Bohm. Born in Wilkes-Barre, Pennsylvania, Bohm had an experience similar to Einstein's involving light. As Briggs and Peat $(1984$, p. 57) related Bohm enjoyed, as a child, looking down from the hills on the streets and houses of this small town. Once, while gazing at the lights below, he realized that the energy from these lights extended out from the town beyond the Earth and into the universe. This light energy was like his thoughts which seemed to travel beyond where he was at a given moment.

Bohm completed his doctoral work with Robert Oppenheimer at the University of Southern California; he was then offered a position at Princeton University where he had the opportunity to meet with Einstein. For six months they discussed the nature of physical theories and the state of quantum theory. Following these conversations, Bohm 
published the book Quantum Theory (1951), in which he advanced some of his earliest ideas on the concepts of wholeness and order.

Throughout his career, Bohm's (1951) primary interest has been in studying "the indivisible unity of the various parts of the world," especially as they relate to an in-depth understanding of consciousness and matter. In a later book Wholeness and the Implicate Order (1981), he used the term "implicate order" (from the Latin root meaning to "fold inward") to refer to any relatively independent element containing within itself the sum of all the elements.

For Bohm, consciousness includes thought, feeling, desire, and will and therefore must be comprehended in terms of an implicate order that applies to living and non-living matter as well as to consciousness. As he stated:

If matter and consciousness could ... be understood together, in terms of the same general notion of order, the way would be open to comprehending their relationship on the basis of some common ground. Thus we would come to the germ of a new notion of unbroken wholeness, in which consciousness is no longer to be fundamentally separated ... (1981, p. 197)

Also relevant to this discussion is Karl Pribram's work regarding the brain and the fact that information appears to be enfolded over the whole. Storage of this kind resembles a hologram in which the pattern of the whole is contained in the parts. Both Bohm and Pribram are very much interested in helping the world understand the order and wholeness that is behind the universe so that it can be activated in our lives and in the lives of those who will live in the coming generations.

In part the urgency of their concern relates to what happens when wholeness is not achieved. Bohm (1981) wrote that "man has sensed always that wholeness or integrity is an absolute necessity to make life worth living ... Yet, over the ages, he has generally lived in fragmentation" (1981, p. 3). Along these same lines, Bohm also stated:

Some might say: "fragmentation of cities, religions, political systems, conflict in the form of wars, general violence, fratricide, etc., are the reality. Wholeness is only an ideal, toward which we should perhaps strive" . . Rather, what should be said is that wholeness is what is real and that fragmentation is the response of this whole to man's action, guided by illusory perception, which is shaped by fragmentary thought. In other words, it is just because reality is whole that man, with his fragmentary approach, will inevitably be answered with a correspondingly fragmentary response. So what is needed is for man to give attention to his habit of fragmentary thought, to be aware of it, 
and thus bring it to an end. Man's approach to reality may then be whole, and so the response will be whole. (1981, p. 7)

Lest we become too "pollyannaish" with these thoughts, we must remember that sometimes chaos also lies within the order of the universe. The same is true in human life where spiritual suffering coexists with spiritual joy. This does not, however, negate the interconnectedness of the whole in which fundamental unity stands behind all diversity.

In the work of Sheldrake, a British biologist, we find the proposal that hidden fields exist that give regular movement and shape to the universe and all therein. These fields, called "morphogenetic," form, within persons, in all systems of the body. They also form in rocks, plants and animals and move in an ascending interlocking order to the human being. Thus, for Sheldrake, the laws of nature are always evolving, and what happens in one place may affect something somewhere else.

On this point of interrelatedness, Sheldrake and Bohm agree to the extent that morphogenetic fields can be considered aspects of the implicate order. They also agree on the unity of human consciousness in which consciousness is a morphogenetic field giving a general shape to each individual consciousness, which forms its own field through memories and experiences. As each individual field resonates, it modifies the general field of human consciousness, and that, in turn, affects the present and future. Thus, the psychological, ethical and moral implications are staggering for, in reality, each individual is responsible for the whole. We can also see here the possible kinship to Carl Jung's idea of archetypes and the collective unconscious. Indeed, such theories move us easily from the realm of physics and biology to a contemplation of the human mind and consciousness.

Is there, for instance, any doubt that the human mind prefers order and simplicity to disorder and complexity? Does wholeness not produce a more harmonious feeling than fragmentation? One of the longdebated questions among scientists and non-scientists alike has concerned the order and unity in nature. As Louise Young has pointed out:

It has been argued that in searching for unity ... scientists have imposed order on nature-that the order we think we have found has no objective reality. It is only a reflection of our own minds. (1986, p. 178)

Many of the discoveries of science, however, have their origin in the handiwork of nature. Rene Descartes found order in the rainbow; 
Newton found the spectrum of colors there also, and in 1925 the great philosopher Alfred North Whitehead wrote these words in Science and the Modern World:

There can be no living science unless there is a widespread instinctive conviction in the existence of an order of things and in particular of an order of nature. (1925, p. 4)

It is important to remember, in seeking to focus and emphasize the importance of wholeness in the universe, that we need both knowledge and insight. When we don't look or act with both knowledge and insight, we threaten the possibility for wholeness. Such is the case with the NDE in that it calls us to explore both the facts about the phenomenon itself and insights into its meaning. And only if we honor both of these activities will we understand the message of the experience, which is always a catalyst for change in the life of the experiencer. Thus, we must turn our attention to the realm of consciousness and contemplate the psyche as an inner cosmos in which the guiding principles are also orderly.

\section{An Adventure in Consciousness}

Much as been written and said about the need for a "recovery," an indepth understanding, and a renewed experience of the intuitive insights of the Primordial Tradition within the major religions of the world. This Primordial Tradition does not refer to a static, cognitive doctrine or dogma that can be scientifically proven by our perfected intellect. Neither does the tradition belong to any particular religion or select group of individuals. Rather its roots are to be found deep within the psyche in what Jung called the collective unconscious of all humankind.

\section{The Roots of Consciousness}

Described by Jung in an overall picture of the psyche that also contains the personal unconscious and consciousness itself, the collective unconscious is a deep reservoir of ancient images, symbols, archetypes and myths common to all peoples everywhere. The importance of this well of psychic building blocks is often overlooked because its influence is difficult to trace. Collective elements almost always ap- 
pear in dreams or complex reactions that are colored by personal associations or conscious intellectualizing.

The real adventure in consciousness is to experience fully and to integrate these aspects as a part of our everyday conscious life. This integrative process, at its best, also includes what I prefer to call the sacred consciousness, which is available to everyone. It may be that this sacred consciousness (that aspect of life which moves us toward wholeness) is never truly unconscious, for its very nature is not buried. This deep source-the "numinous," the spirit or spark of divine energywithin all individuals inspires them to holiness and wholeness. It appears that this may occur because the numinous is pure spirit (pure light energy) that can not be isolated, controlled, or monopolized by any person or set of ideas and has at its core a sense of conscience, a knowledge of right and wrong. Thus, from the action of the spiritual impulse on universally stored archetypal patterns comes the Primordial Tradition-the intuited expression of direct spiritual experience.

In addition to the Primordial Tradition, and also related to the collective unconscious, is another body of material that stands outside the codified religions of the world. It includes folklore, legends, cultural mores, and the ritual practices of indigenous peoples, many of whom have sought to live in their communities, some for the past 40,000 to 50,000 years. Among these are Native Americans, Aborigines of Australia, Maoris of New Zealand, tribal peoples of African countries, natives of South and Central America, and many others. Archaeology is now discovering much that connects us with these peoples through common symbols, signs and myths. Of particular importance to the field of near-death studies are the concepts and rituals surrounding the experience of death. Kenneth Maddock, in his book The Australian Aborigines (1974), noted, regarding their concept of death:

The interest Aborigines show in death is connected with their view of the person as divided between body and spirit. In life the two are united, but their permanent separation means death-in a bodily sense at least, for the spirit survives. (p. 142)

Spirit exists before birth (having entered the mother) and continues to exist after death . . . But although spirit is independent of flesh in the sense of outlasting their separation, it is thought to hang about its former home. This habit is broken through a series of ritual observances (p. 152)

Although these words do not speak directly of near-death experiences, they relate to our discussion in several ways. First, the near- 
death experiencer often encounters spirits who are deceased, and such encounters are a vital part of the cultural heritage of people who are among the oldest indigenous groups known in the world today. The spirit encounter is also a part of our own cultural experience, in folklore and literature, as well as in certain of our afterlife concepts. Thus, science can say to us, and rightly so, that these experiences are a part of the collective databank available to all persons in certain altered states of consciousness. The question is how such experiences are called forth and whether beliefs actually have certain vibrations or waves or light energies that can be tapped in dreams, out-of-body experiences, the NDE, or other alternate reality experiences.

Second, although it may be important to recapture the Primordial Traditions of organized major religions, it is likewise important to recapture those beliefs and practices that have grown up, not around the teachings of certain leaders and holy men, but through the everyday personal encounters with life and death among peoples who have never been separated from the direct experience of nature. Their mystical and intuitive responses to natural phenomena represent a body of truths constellated within the psyche and presented to us through metaphor and symbol.

\section{Consciousness, Thought and Survival}

Thus, we begin to see that the real issue between religion (spirit) and science (matter) lies in the data of consciousness studies. It is consciousness that eludes us; it is consciousness that can not be isolated. Our difficulty is in knowing exactly what happens when one is in a state of consciousness that seems to defy the norm, or what we tend to accept as our everyday waking sense of time and space.

Walter Russell, in The Secret of Light (1947), proposed these thoughts on the subject:

What [man] calls his subjective mind is his consciousness, his spiritual storehouse of all-knowledge, all-power, and all-presence. That consciousness is his Self, his ETERNAL Self through which his omniscience, omnipresence and omnipotence is expressed as he slowly becomes aware of their presence within him.

... Nor does he yet know that consciousness never sleeps, never changes, for consciousness in man is his immortality. It is the LIGHT which he is unknowingly seeking ... (pp. 3-6)

It is not possible, therefore, for us today to understand the near-death experience without recognizing that we are exploring an altered state 
of consciousness - that is, a state different than normal waking consciousness. Nor is it possible for us to speak of the NDE without a conscious association or thought about the phenomena of light. And it's also important for us to understand that an altered state may operate under altered "rules," may, in fact, operate in ways that are totally unpredictable. Take, for instance, J. H. Hacsi's description, in The Universe That Isn't (1985), of the world of the scientist. This is a world in which, for centuries:

the speed of light is the outside limit. Nothing can travel faster than light. According to Einstein's predictions, if an object could reach the speed of light its length would be reduced to nothing and its mass, that is, its resistance to change of speed, would become infinite. Yet the photon, the quantum particle of electromagnetic radiation, traveling at the speed of light, far from having infinite mass is considered to have no mass at all, to be massless. (Hacsi, 1980, p. 59)

Most school children know today that the accepted velocity of light is 186,000 miles per second across "empty" space, or a vacuum. Science also tells us that a vacuum is space devoid of matter-something that really doesn't exist on Earth, or possibly anywhere else for that matter. Much has been debated also about the wave theory and the particle theory of light. Modern science currently accepts the fact that light is a wave and a particle; that it acts at times as a particle, and that particles have associated waves.

The next question for us, recognizing the place of light in our universe and the speed with which it travels, involves the issue of thought communication as it relates to consciousness. Is it possible that thought transference, through telepathy, may travel faster than light travels? This phenomenon is not uncommon among persons who have emotional, intimate, or intense connections with each other (including identical twins, parents and their children, couples) but are spatially separated.

It is important to note here that when we raise questions involving the speed of thought, we are not talking about the speed of electric impulses as they occur within the brain where we recognize that mental activity is tied to the physical in some ways that we may as yet only partially understand. Rather, the issue concerns the transmission of thought through the air (or ether waves) from one mind to another mind. Is it possible that this transference of knowledge is instantaneous, and neither slower nor faster than the speed of light? Could it be that the speed of thought and the speed of light are the same? If so, then what might be the connections between thought waves and light waves? And do both thought and light share the common characteris- 
tics of being massless? Another question this connection raises is whether we might envision or construct a universe, or other things, built on thought rather than on light-or electromagnetic radiation that reaches us as visible light.

These may seem like preposterous questions, irrelevant to life, and against belief structures; yet, they could actually be the foundation from which many questions about the near-death experience are raised by both skeptics and researchers. And it is here that we must carefully consider our methodology and our commitment to orthodoxy. Although we do need-in our studies-to apply scientific methods, pursuing each question to the next and the next, we need also to recognize that some questions can't be followed from the stage of theory to observable fact and that we must at certain times be willing to heed the words of the Gautama Buddha, who is purported to have said to his disciples:

Believe nothing which is unreasonable, and reject nothing as unreasonable without proper investigation.

There also exists the possibility that telepathic thought does not travel from one mind to another mind but rather appears spontaneously in the appropriate mind at the appropriate time. Possibly the thoughts exist everywhere at a given time-that is, even outside the space/time continuum of the plane of existence of this planet, and are picked up by those who are affected or connected to the person/persons involved.

Given the bent of this discussion, we might now ask, Do consciousness and thought dwell within the domain of Einstein's Theory of Relativity, as represented by the equation $\mathrm{E}=\mathrm{mc}^{2}$ (energy equals mass times the speed of light squared)? If mass can be converted into energy (and vice versa) and still the sum total of mass/energy in any system, despite various changes, is always present, then is it possible that thought itself is a form of mass/energy? If not, then the dilemma becomes, what is thought, and what is consciousness?

We know that either stimulus or the lack of it, internally or externally, causes thought. Thus, it is a physiological process in which chemical and electrical happenings in the brain set in motion the appearance of memories, symbols, images, feelings, associations and other aspects of unconscious material. Therefore, thought does not arise out of nowhere, but rather arises, apparently, out of the alive, healthy, physical brain. Another possibility exists, that thought may also arise out of the mind/consciousness beyond the brain, for if mass and energy are neither created nor destroyed, they are always present in time and space. 
The essence of thought and consciousness is thus an important issue not only when we consider the way the mind functions in the universe but how or whether it survives the body's death. The near-death experience has focused for the world major questions regarding life, death, the afterlife, and survival. Within a completely scientific paradigm, proof, in these areas, is very difficult-certainly for those who remain among the living!

For the most part we have become sophisticated enough in our belief systems to recognize that the body we inhabit in this world is not the vehicle that will take us beyond the physical plane. With our current understanding of dimensions of consciousness, however, we can, to a certain degree, conceive of other bodies-astral, ethereal, or mentalthat may have form but not the flesh and blood necessary for life in this atmospheric pressure. For some individuals, such ideas are beyond the realm of proven fact and therefore irrelevant. Yet, facts are difficult to come by without the ability to draw information and conclusions from experiential models. Scientifically speaking, survival, in essence, doesn't give us much to go on.

Two main assumptions regarding the survival of the soul are given to us by various religious and philosophical belief systems. One proposes that the soul, after death, resides in a specific place; the other has the soul returning to another life in another body for several possible reincarnations. Within each of these assumptions, are many possible configurations. The idea of a final resting place, for instance, may include a time of judgment, a place of abode-either Heaven or Hell, redemption by a religious figure or savior, the resurrection of the body, and a last judgment. Reincarnation, on the other hand, offers a longer or shorter stay on what may be the "astral plane," after which the soul comes once again to Earth and selects or is given a new vehicle (depending on the deeds of the past life or lives) in either the human or animal kingdom.

A third survival possibility, however, must be considered, based on a scientific understanding of the universe. If the universe is expanding, if nothing is ever lost but merely changes composition, and if the unified principle of wholeness is an option, then it may be possible that some configuration exists that we have not yet uncovered-a configuration born of oneness and interconnection. In some respects, we might say that theology, religion, psychology, cultural history, and personal need have "lobbied for" the idea of the survival of the human personality, building on this model their concepts of an afterlife and reincarnation. Perhaps it is time to see what a new model, steeped in the understanding of a holistic universe, would have to offer. In order to 
develop such a model, we must take some risk, leaving behind preconceived ideas, outdated teachings, and subjective experiences.

Another important issue arises from our contemplation of the neardeath and other related experiences. This is the issue of transformation and transcendence in human life. We are not, today, the Neanderthal of yesterday, and we may not be tomorrow the being we perceive ourselves to be today. The great Indian sage, Sri Aurobindo, whose work continues today in Pondicherry, India, and around the world, is one of the people of this century who has envisioned a "New Evolution." These are his words offered to us by Satprem in On the Way to Supermanhood (1985):

Man is a transitional being; he is not final.

The step from man to superman is the next approaching achievement in the earth's evolution.

It is inevitable because it is at once the intention of the inner Spirit and the logic of Nature's process. (Satprem, 1985, p. 1).

If we are seeing shifts or expansions in consciousness today, is it inconceivable that we are only preparing the way for what is to come?

Unfortunately, with civilization's advancement, technologically and culturally, we have become more and more specialized, and we feel a need to put everything in a little box and label it. Sometimes, however, out of the greatest chaos a new phoenix rises. We need to be open to this rarest of birds by not locking the cage too quickly on the interpretation of human experience, including the NDE. Let us accept what the experience offers us in terms of current scientific understanding, then step back and observe the same data with our intuitive selves. Out of the variety of human experience, one moment will transcend this place and time and speak to the future. None of us knows what that moment will be.

\section{A Metaphoric Encounter with the Essence of Light}

In the cosmos, both inner and outer, that we've discussed thus far, light has consistently been viewed as sacred. When the near-death experiencer is immersed in the light, he or she enters a realm of knowing that transcends the process of thinking. On this level consciousness is static and of the one light. There also the experiencers know they have arrived at a sacred mountain, so to speak, and are in the presence of a magnetic light in which there is absolute stillness. At 
this place, the light, although it may last for only a matter of seconds, neither attracts nor repels but is all stillness, peace, and calm.

Another aspect of the light's presence is that often it reveals its essential character to us through scenes of nature-the color, shape, and form of landscapes; trees, hills, mountains, and other pastoral images. In these scenes, NDErs often receive nature's secrets, which are whispered to them amid the stillness and beauty. This reminds us that the Aramaic word for light is noohra, which also means "enlightenment" and "understanding." Biblically, in the Judaic and Christian traditions, the term light symbolically represented God, Yahweh, His Word, or a true teaching. Psalm 119: 105 (King James Version) states:

"Thy word is a lamp to my feet and a light to my Path."

In Genesis, light is linked with Creation. That is, on the first day of Creation, light appeared. It has been speculated that the author of Genesis was a prophet/physicist who knew, as we do today, that everything in the universe could be reduced to light, light being the essence of all matter. Today we speak of matter as gravitationally trapped light (or a form of energy) that is the source of humankind's physical existence on Earth.

\section{The Mystery of Light: Walter Russell and Omraam Mikhael Aivanhov}

Actually, the mystery of light begins for us with the realization that light can not be seen. It is hard for us to know something that can not be seen. The same is true of air, breath, space and time - to name only a few concepts relevant to the topic of light. Light is something we live with daily but do not fully understand. Nor do we begin to comprehend its complexity. It is as if our eyes "feel" light. This is probably but a vibration or electrical wave motion that simulates the idea of light. The actual idea of light, however, can not be produced, for the waves only simulate the idea and do not actually become the idea.

We know today that when we see the light of the sun, the nerves of our eyes are feeling the intense, rapid, short wave vibration of the kind of wave motion we sense as incandescence. We are so accustomed to the idea that we see light in various intensities that it is difficult for us to accept the fact that our own senses act as mirrors to reflect various intensities of wave motion. This same phenomenon is true for darkness. We do not see darkness; rather the nerves of our eyes sense the 
slowdown of motion to a rate of vibration at which we no longer feel the movement.

In any discussion of the nature and essence of light, my thoughts turn automatically to the work of two important but not widely known teachers: Walter Russell and Omraam Mikhael Aivanhov. For twenty years now I have been fascinated by the life and work of Russell. He was born on May 19, 1871, in Boston, Massachusetts, attended village school until he was nearly ten and, due to family circumstances, had to leave school to work. His first job was as a cash boy in a dry goods store for $\$ 2.50$ per week. He walked six miles a day to and from work. At thirteen, he secured a church organist's position (he had been a musician since childhood), then entered art school. As Glenn Clark reported, in The Man Who Tapped the Secrets of the Universe (1973), Russell considered himself fortunate to have escaped the "educational systems of informational cramming and memory-testing which filled other children's lives until they were twenty-five" (Clark, 1973, p. 12).

He lived for years in New York City and made his living very credibly in variety of fine arts-music, literature, architecture, painting and sculpture. He also made discoveries in science and had an international reputation as a philosopher and lecturer in the fields of ethics, spirituality and human relations.

When asked by Clark, in a 1946 interview, "What is the great passion of your life?" Russell replied without hesitation, "Beauty ... Beauty and worthiness to live life as a masterful interpreter of the Light" (Clark, 1973, p. 21). His own discoveries, however, caused him to see not beauty but destruction by man's hands. He foresaw two of the greatest discoveries of the 20th century - the isotopes of hydrogen, which led to the discovery of heavy water, and the two new elements used in the atomic bomb. He announced the complexity of hydrogen to a body of distinguished scientists years before the truth of his statement was verified. The two newly discovered elements that formed the base of the atomic bomb, called Neptunium and Plutonium, were published in his Charts of the Elements in 1926. He named the elements Uridium and Urium.

Much of the knowledge recorded in books by Russell (and some coauthored by his wife Lao Russell, who died in 1988) came to him during a light experience he had in May of 1921. For many days and nights he was made to write down all the things that he knew in The Message of the Divine Iliad, which is the record of this teaching while in the light. He said:

Thus I was made to see the universe as a whole and its simple principle of creation as one unit, repeated over and over, endlessly and 
without variation, as evidenced in the universal heart-beat to which every pulsing thing in the light-wave universe is geared to act as one unit of one whole. (Clark, 1973, p. 35)

He went on to say:

No greater proof than my experience is needed to prove to the doubting world that all knowledge exists in the mind universe of Lightwhich is God - that all Mind is one mind, that we do not have separate minds, and that all knowledge can be obtained from the Universal Source of All Knowledge by becoming ONE with that Source. (Clark, 1973 , p. 36)

These thoughts are echoed in the work of Aivanhov (1900-1986), a Bulgarian spiritual teacher, who moved to France in 1937. In his book, Light is Living Spirit (1987), Aivanhov discussed the two Bulgarian words for light:

... svetlina, the physical light that we can see, and videlina, the spiritual, primeval light created by God on the first day, when he said, 'let there be light!' It was only on the fourth day when God created the Sun and Moon and Stars, that svetlina appeared as a more material manifestation of videlina. And the Sun-which is not a ball of fire as most people think, but a living conscious entity - the sun receives the subtle invisible light, videlina, and transforms it into visible light, svetlina, thanks to which it shines for the whole universe. It is this quintessence of light, videlina that is so powerful. (Aivanhov, 1987, p. 142)

It has been said that light is everywhere in space, even in Black Holes; although it permeates everything, however, we are unable to see it because of our undeveloped spiritual faculties. Is this what the aura is all about? The ancients tell us that if we concentrate on light enough, we feel it, we attract it, and it begins to penetrate us and change us. It is the light that restores us to complete harmony; it is the light that heals us, and light is the breath (the prana) we breathe. Isn't that the real secret of life, that the breath we breathe-the lightignites the machines we call our bodies?

Today, we have also been told that ancient civilizations, such as the one called Atlantis, used to collect and condense the light of the Sun by means of huge crystals. It is believed that this energy was then used to run instruments and machines.

\section{The Laser, The Hero's Quest, and the NDE}

In the early 1960s, American physicist Theodor Marman developed the technique of the laser. The term LASER is formed from the first 
letters of the words "light amplification by stimulated emission of radiation." The laser is light that is concentrated into a single beam of tremendous power that can be used to perform many different extraordinary operations. In an ordinary light beam the rays go off in all directions, but the laser produces one intensely concentrated, undiffused beam of "coherent" light flowing in one direction with all its waves of the same wavelength-thus, monochromatic. These unique characteristics make it an invaluable instrument. For instance, in military projects it is able to pulverize spatial ships at a great distance. It can measure the altitude of approaching aircraft, and it can locate the position of an enemy through all intervening obstacles. From the laser, in effect, there is no hiding place.

In addition to their military uses, lasers drill holes in diamonds, weld the retina of an eye to its support, perform surgery on parts of single cells, and slice through huge piles of thick materials. Who knows, perhaps this is the secret that helped the Egyptians cut and build the pyramids in the land of the Sun.

Allan Maurer, in his book Lasers: the Light Wave of the Future (1982), ended with these words:

Entirely new and radically different kinds of lasers will probably appear-and as our knowledge of light and matter grows, lasers will make practical what can barely be done today and make possible what is not yet even dreamed of.

Is it possible that in the future nothing will be more important than exploring light? Is it possible that this light-the laser-is in reality, like the soul, the spark of the sacred within everything, and is it possible that this is what the search for consciousness is all about? Is the mysterious light of the NDE a laser to the self-a soul in another dimension of consciousness? Or, is it a fragment of the consciousness of the human brain/mind?

On a symbolic level, what we see in the NDE, when we look specifically at its "story" or narrative framework, may be thought of as a journey or spiritual quest. The quest motif, identified by Joseph Campbell in his book The Hero With a Thousand Faces (1949) is a pattern common to all mythologies, all literatures, and all stories, no matter how simple or how complex. As distilled by Campbell, the journey focuses on a hero (man or woman) who is called to adventure, receives supernatural aid, crosses the threshold to another world, pursues the road of trials, earns the ultimate boon, and returns to the old reality 
(often unwillingly) a changed person who then must reconcile what has been "revealed" with what exists.

In the NDE, the revelatory moments are generally surrounded by light. If we think about it, revelation is always an experience of light. It is the light that "dawns" in any situation to show us the true nature of things - the connections that exist and the direction demanded by those connections. Revelation, therefore, is always the goal for the hero/experiencer. Mythologically speaking it is the god-energy, the spark of divinity at the center of the maze; psychologically, it is the hero's momentous meeting with his or her own androgynous self, and historically or sociologically, it is the gift brought back from the journey to enlighten the world.

This is not to say that revelation is always a pleasant or sought after experience; the light of God can be fatal to look upon. It is, however, a necessary encounter for growth and transformation in the life of any individual. While the hero/experiencer may refuse the call to the quest, no one comes back unchanged from the journey. Yet, revelation is not a pure experience of the divine. It is always filtered through the personality, the mind, and the brain that experience it, and the change that is wrought is a change in the fundamental emotional structure of the individual.

What then is the nature of this change? Basically, it is a response to the essence of revelation-to the connections uncovered by that brilliant, all-embracing light-and those connections are both personal and universal. They are personal in that they show, often in the form of a life review, the effects of action and decision on past and immediate circumstances; they are universal in that they open the individual spirit to ultimate truth and move the heart to compassion. Listen to Campbell's description of the hero at the moment of revelation and choice:

Turning his regard from the inner sphere of thought-transcending truth ... outward again to the phenomenal world, he perceives without the same ocean of being he found within ... And he is filled with compassion for the self-terrorized beings who live in fright of their own nightmare. He rises, returns to them and dwells with them as an egoless center. (Campbell, 1949, pp. 165-166)

And although for the near-death experiencer, the great spiritual truth that is learned may lie beyond the realm of the spoken word, the compassion that floods the heart will change the way the person lives from that day forward. 


\section{Conclusion}

Experiences involving the nature of light, like the NDE, may one day lead us to the spiritual realm (the unknown we've called God) by methods and standards that can be acceptable to both science and religion. But only when the spiritual foundation is laid can science and religion, the two disciplines of greatest concern to the civilization of planet Earth, hope to find a unity, effect a marriage, and share a life together.

If this marriage takes place, all human relationships and every compartment of life will function in a more balanced way because we will have greater knowledge of the universal law that lies behind our many-faceted, vibrating, electric wave universe. Through our study of the NDE, we have the opportunity to touch this universal law by participating in an experience of wholeness, by rediscovering our sacred consciousness through an exploration of the mind, and by experiencing light as a metaphor for spiritual truth. These encounters are fundamental to our sense of who we are and where we're going.

Thus, as we contemplate the very important questions raised by the NDE, let us look at these issues in the light of evolutionary history. Scientists tell us there have been generations of stars. As some were born, others died, and through this cycle the synthesis leading to life came about. This creative work is now twenty billion years old, and some believe that Homo sapiens has walked the earth for only a hundred thousand of those years. This alone should give us pause!

As we leave here, pondering seriously all the answers we do not have, may we not ponder so seriously that we forget to enjoy ourselves and each other in this great game we play called life. In the words of the immortal bard:

Our revels now are ended. These our actors, As I foretold you, were all spirits, and

Are melted into air, into thin air;

And, like the baseless fabric of this vision, The cloud-capped towers, the gorgeous palaces,

The solemn temples, the great globe itself, Yea, all which it inherit, shall dissolve, And, like this insubstantial pageant faded, Leave not a rack behind. We are such stuff As dreams are made on, and our little lives Are rounded in a sleep. 


\section{References}

Aivanhov, O. M. (1987). Light is a loving spirit (2nd ed.). Frejus, France: Prosvetta Editions.

Bohm, D. (1951). Quantum theory. Englewood Cliffs, NJ: Prentice-Hall.

Bohm, D. (1981). Wholeness and the implicate order. London, England: Routledge and Kegan Paul.

Briggs, J. P., and Peat, F. D. (1984). Looking glass universe: The emerging science of wholeness. New York, NY: Simon and Schuster.

Campbell, J. (1949). The hero with a thousand faces. Cleveland, OH: World Publishing.

Clark, G. (1973). The man who tapped the secrets of the universe Waynesboro, VA: University of Science and Philosophy.

Einstein, A. (1979). The world as I see it New York NY: Philosophical Library.

Hacsi, J. H. (1985). The universe that isn't (the reality that is). West Covina, CA: Champagne Press.

Hanson, V. (Ed.). (1988). H. P. Blavatsky and the secret doctrine (2nd ed.). Wheaton, IL: Quest/Theosophical Publishing.

Jastrow, R. (19777). Until the sun dies. New York, NY: Norton.

Maddock, K. (1974). The Australian Aborigines (A portrait of their society) (2nd ed.). New York, NY: Penguin.

Maurer, A. (1982). Lasers: The light wave of the future. New York, NY: Arco.

Russell, W. (1947). The secret of light. Waynesboro, VA: University of Science and Philosophy.

Satprem. (1985). On the way to supermanhood. New York, NY: Institute for Evolutionary Research.

Whitehead, A. N. (1925). Science and the modern world. New York, NY: Macmillan. Young, L. B. (1986). The unfinished universe. New York, NY: Simon and Schuster. 